PACS 32.80.Rm; 05.45.+b;

УДК 539.184, 539.186

\title{
SENSING THE TOKAMAK PLASMA PARAMETERS BY MEANS HIGH RESOLUTION X-RAY THEORETICAL SPECTROSCOPY METHOD: NEW SCHEME
}

\author{
Yu. G. Chernyakova, V. M. Ignatenko and L. A. Vitavetskaya \\ Institute of Applied mathematics OSEU, P.O.Box 108, Odessa-9, 65009, Ukraine \\ Phone: +380-482-637227 E-mail: glushkov@paco.net
}

\begin{abstract}
SENSING THE TOKAMAK PLASMA PARAMETERS BY MEANS HIGH RESOLUTION

X-RAY THEORETICAL SPECTROSCOPY METHOD:

NEW SCHEME

Yu. G. Chernyakova, V. M. Ignatenko and L. A. Vitavetskaya

A new high resolution theoretical spectroscopy scheme is developed and used for sensing and diagnostics the tokamak plasma parameters. Some numerical illustrations regarding sensing the tokamak plasma parameters (electron temperature etc.) and calculation results for wavelengths atomic characteristics of satellite spectrum of the He-like ions from $\mathrm{Ar}^{16+}$ to $\mathrm{Mn}^{23}$ are presented and are in a good agreement with the tokamak de Fontenau-aux-Roses measurements..
\end{abstract}

Key words: tokamak plasma, parameters sensing, theoretical spectroscopy method

\section{Анотація \\ ДЕТЕКТУВАННЯ ПАРАМЕТРІВ ПЛАЗМИ ТОКАМАКА НА ОСНОВІ МЕТОДУ ВИСОКО ВИРІШЕНОЇ РЕНТГЕНІВСЬКОЇ ТЕОРЕТИЧНОЇ СПЕКТРОСКОПІЇ: HOBA CXEMA}

\section{Ю. Г. Чернякова, В. М. Ігнатенко, Л. А. Вітавецька}

Запропонований новий метод високо вирішеної рентгенівської теоретичної спектроскопії для детектування та діагностики параметрів плазми токамака. Приведені чисельні илюстрації визначення параметрів плазми токамака (електронна температура тощо), а також результати розрахунку довжин хвиль і атомних характеристик сателітних спектрів для Не-подібних іонів від $\mathrm{Ar}^{16+}$ до $\mathrm{Mn}^{23+}$, які знаходяться у добрій згоді із даними вимірювань на токамаці de Fontenau-aux-Roses.

Ключові слова: плазма токамака, метод детектування, теоретична спектроскопія 


\title{
Аннотация \\ ДЕТЕКТИРОВАНИЕ ПАРАМЕТРОВ ПЛАЗМЫ ТОКАМАКА НА ОСНОВЕ МЕТОДА ВЫСОКО РАЗРЕШАЕМОЙ РЕНТГЕНОВСКОЙ ТЕОРЕТИЧЕСКОЙ СПЕКТРОСКОПИИ: НОВАЯ СХЕМА
}

\section{Ю. Г. Чернякова, В. М. Игнатенко, Л. А. Витавецкая}

\begin{abstract}
Предложена новый метод высоко разрешаемой рентгеновской теоретической спектроскопии для детектирования и диагностики параметров плазмы токамака. Приведены численные иллюстрации определения параметров плазмы токамака (электронная температура и т.д.), а также результаты расчета длин волн и атомных характеристик сателлитных спектров для Не-подобных ионов от $\mathrm{Ar}^{16+}$ до $\mathrm{Mn}^{23+}$, находящиеся в хорошем согласии с данными измерений на токамаке de Fontenau-aux-Roses.
\end{abstract}

Ключевые слова: плазма токамака, метод детектирования, теоретическая спектроскопия

In last years a great attention is turned to problems of experimental and theoretical study of high temperature multi-charged ions plasma and developing the new diagnostics methods (c.f. [14]). Similar interest is also stimulated by importance of carrying out the approaches to determination of the characteristics for multi-charged ions plasma in thermonuclear (tokamak) reactors, searching new mediums for X-ray range lasers. The X-ray laser problem has stimulated a great number of papers devoting to development of theoretical methods for the modelling the elementary processes in a collisionally pumped plasma. The current trend is to study high $\mathrm{Z}$ elements. There is a hope to find lasing effects on the transitions in plasma of the Li-, Ne-, Ni-like ions. Very shocking example is a scheme for accomplishing tabletop x-ray lasing in Li-like ion of $\mathrm{Ne}$ at $98 \AA$ in an optically ionized plasma during recombination in the transient regime which was carried out in the Lawrence Livermore National Laboratory (University of California) [4]. Saturation effects and parametric heating processes by stimulated Raman scattering are analyzed and found to allow energy efficiencies in excess of $10^{-5}$ for a 100 fsec duration, $0.25-\mu \mathrm{m}$ laser driver of intensity $10^{17} \mathrm{~W} / \mathrm{cm}^{2}$. Significant improvement in efficiency is indicated for shorter laser pulse lengths. At the same time, low temperature plasma sources are more efficient and less expensive devices. They show promise for producing lasing in the vacuum ultraviolet and soft X-ray region. Preliminary investigations of capillary spark discharge were made (c.f.[1-4]), which show the possibility of their use as effective plasma sources for the generation of a soft-X-ray or extreme ultraviolet amplified spontaneous emission. A great progress in development of laser technique, tokamaks and accelerators experiments resulted to a new class of problems in the plasma physics and correspondingly diagnostics of their parameters. The electron temperatures and particle confinement times in tokamak plasmas permit the ionization of the heavy impurity elements up to the helium-like (eventually hydrogen-like) charge state. High resolution spectroscopy of the line emission of these ions has become a powerful technique for determining the electron and ion temperatures $T_{e}$ and $T_{i}$, the macroscopic plasma movement and dynamics of the plasma impurity transport. Experimental measurements have beer carried out by means of Bragg crystal spectrometers, high quality spectral analysis for diagnostic-relevant impurities at several large tokamaks: $\mathrm{Ti}^{20+}$ and $\mathrm{Fe}^{24+}$ (Princeton Large Torus), $\mathrm{Cr}^{22+}$ (tokamak de Fontenauaux-Roses=TFR) etc [1-4]. The TFR measurements of the plasma parameters and wavelengths, atomic characteristics of satellite spectrum of the He-like ions from $\mathrm{Ar}^{16+}$ to $\mathrm{Mn}^{23}$ (Ar, Sc, V,Cr, Mn) are accurately carried out and presented in ref. [2].

Two key theoretical problems must be solved in order to develop a special code and to predict necessary plasma parameters needed for sensing the plasma parameters. First one is a highly accurate definition of the rate coefficients for elementary processes in the plasma that are responsible for the forming emission lines spectra. The second problem is connected with necessity of development new adequate calculation schemes for defining the wavelengths, level populations, inversions, line intensities etc. at definite plasma parameters. Despite of great number papers, devoting to solving cited problems (c.f. [1-12] and references in them), they are at present time 
quite far from final adequate solution. The most consistent approach to considered problems solving must base on the quantum electrodynamics (QED). In ref. [16-18] two new consistent QED versions for calculations of the spectroscopic characteristics of the multicharged ions in plasma have been developed. Here we use these high resolution theoretical spectroscopy schemes for sensing and diagnostics the tokamak plasma parameters. Some numerical illustrations regarding sensing the tokamak plasma parameters (electron temperature etc.) and calculation results for wavelengths atomic characteristics of satellite spectrum of the He-like ions from $\mathrm{Ar}^{16+}$ to $\mathrm{Mn}^{23}$ are presented and are in a good agreement with the tokamak de Fontenau-aux-Roses measurements.

Let us now describe the key moments of the two new consistent QED versions for calculations of the spectroscopic characteristics of the multicharged ions in plasma, which have been developed in ref. [16-18] and based on the gauge invariant QED energy approach [9-13]. Both theoretical spectroscopy perturbation theory (PT) schemes allow calculating spectra and spectroscopic characteristics of neutral atoms, multicharged ions with account of relativistic, correlation, nuclear, QED effects. The version [16] allows to take into account the QED, radiative effects; version $[17,18]$ allows to account for the correlation effects and should be used in calculation of not very heave atomic systems. It does not account for the QED effects. The wave functions zeroth basis is found from the Dirac equation solution with potential, which includes the core ab initio potential, electric, polarization potentials of nucleus (the gaussian form for charge distribution in the nucleus is used). All correlation corrections of the PT second and high orders (electrons screening, particle-hole interaction etc.) are accounted for. The nuclear potential is provided by choice of the charge distribution in the nucleus as the Gaussian function:

$$
\rho(r \mid R)=\left(4 \gamma^{3 / 2} / \sqrt{\pi}\right) \exp \left(-\gamma r^{2}\right)
$$

Here $\gamma=4 / \pi R^{2} ; R$ is an effective nucleus radius, defined as: $R=1.60 \times 10^{-13} \mathrm{z}^{1 / 3}(\mathrm{~cm})$. The Coulomb potential for spherically symmetric density $\rho(r \mid R)$ is:

$$
V_{\text {nuсl }}(r \mid R)=-\left((1 / r) \int_{0}^{r} d r^{\prime} r^{\prime 2} \rho\left(r^{\prime} \mid R\right)+\int_{r}^{\infty} d r^{\prime} r^{\prime} \rho\left(r^{\prime} \mid R\right)\right.
$$

Let us consider the Li-like ion as example. One can write the DF-like equations for a three-electron system $1 s^{2} n l$ j. Formally they fall into oneelectron Dirac equations for the orbitals $1 s, n l j$ with potential:

$$
V(r)=2 V(r \mid 1 s)+V(r \mid n l j)+V_{e x}+V(r \mid R) .
$$

This potential includes the electrical and polarization potentials of the nucleus. The part $V_{e x}$ accounts for exchange inter-electron interaction. The main exchange effect will be taken into account if in the equation for the $1 s$ orbital we assume $V(r)=V(r \mid 1 s)+V(r \mid n l j)$ and in the equation for the $n l j$ orbital $V(r)=2 V(r \mid 1 s)$. The rest of the exchange-correlation effects are accounted for in the first two PT orders by the total inter-electron interaction $[11,14,15]$. The core electron density is defined by iteration algorithm within gauge invariant QED procedure [13]. Other details of the calculation procedure, including definition of the matrix elements of the QED PT with effective account of the exchange-correlation effects can be found in ref. [9-18]. In all calculations the complex of molecular programs "Superatom" has been used.

The spectral lines we are concerned with in this paper the characteristic lines $\mathrm{w}, \mathrm{x}, \mathrm{y}, \mathrm{z},\left(1 s^{2 l} S_{0}-1 s 2 p\right.$ $\left.{ }^{1} P_{l},{ }^{3} P_{2},{ }^{3} P_{l}, 1 s 2 s{ }^{3} S_{l}\right)$ of the helium-like ion and associated satellte lines of the Li-like type $1 s^{2} 2 l$ $1 s 2 l 2 p$ produced by dielectronic recombination to, or inner-shell excitation of , the lithium-like ion. The most prominent helium-like and satellite lithium-like lines are given in tables 1 and 2

With respect to the intensities of the spectral lines one should note that the line, say, q (see table 1) is mainly due to collisional excitation of the lithium-like ion (c.f.[2]). Neglecting recombination and cascade effect for $\mathrm{w}$, the ratio of the local emissivities of these lines is $\varepsilon_{q} / \varepsilon_{w} \sim 2 / 3 n_{L i} / n_{H e}$, where $\mathrm{n}_{\mathrm{Li}}$ and $\mathrm{n}_{\mathrm{He}}$ are the densities of the Li- and He-like ions, respectively (from optically thin plasmas the ratio of the line-of-sight integrated emissivities is observed) [2]. For a satellite (s) line which is excited mainly by dielectronic recombination from the He-like to the Li-like ion one can right:

$$
\begin{gathered}
\varepsilon_{q} / \varepsilon_{w}=F_{1}\left(s, T_{e}\right) F_{2}^{*}(s) / C_{w}\left(T_{e}\right), \\
F_{1}\left(s, T_{e}\right)=\left(1,65 \cdot 10^{-22}\right) T_{e}^{-3 / 2} \exp \left(-E_{s} / T_{e}\right)
\end{gathered}
$$


where $\mathrm{E}_{\mathrm{s}}$ and $\mathrm{T}_{\mathrm{e}}$ are in $\mathrm{eV} ; \mathrm{F}_{2}^{*}(\mathrm{~s})$ is a line-specific intensity factor given in table $1 ; C_{w}\left(T_{e}\right)$ is the rate coefficient (in $\mathrm{cm}^{3} / \mathrm{s}$ ) for collisional excitation of line $\mathrm{w} ; \mathrm{E}_{\mathrm{s}}$ is the difference in energy of the satellite state in the recombined ion and the ground state in the recombining ion [2-4]. The $\varepsilon_{q} / \varepsilon_{w}$ ratio may be used as a diagnostic for the electron temperature (provided the electron velocity distribution in Maxwellian). In ref. [2] it was indicated that the $\varepsilon_{q} / \varepsilon_{w}$ ratio increases very rapidly with increasing nuclear charge $\mathrm{Z}$ due to mainly the $\mathrm{Z}^{4}$ dependence of the radiative transition probability $\mathrm{A}_{\mathrm{r}}$ in the expansion $F_{2}{ }^{*}(s)$. It is instructive to make use of a z-scaling law for the $C_{w}\left(T_{e}\right)$ of two elements $\mathrm{A}$ and $\mathrm{B}$ as [2]:

$$
C_{w}{ }^{A}\left(T_{e}\right)=\gamma^{3 / 2} C_{w}{ }^{B}\left(\gamma^{2}, T_{e}\right)
$$

where $\gamma=\left(Z_{B}-0,5\right) /\left(Z_{A}-0,5\right)$.

Calculated wavelengths and satellite intensity factors $\left(\lambda\right.$ in $\AA ; F_{2}{ }^{*}$ in $\left.10^{13} s^{-1}\right)$ : Ar

Table 1

\begin{tabular}{|c|c|c|c|c|}
\hline Line & Array & $\lambda[2]$ & $\lambda$ (this paper) & $F_{2}{ }^{*}$ \\
\hline W & $1 s 2 p^{l} P_{1}-1 s^{2 l} S_{0}$ & 3,9457 & 3,9461 & - \\
\hline $\mathrm{X}$ & $1 s 2 p^{3} P_{2}-1 s^{2 l} S_{0}$ & 3,9632 & 3,9636 & - \\
\hline $\mathrm{S}$ & $1 s 2 s 2 p^{2} P_{3 / 2}-1 s^{2} 2 s^{2} S_{1 / 2}$ & 3,9648 & 3,9652 & 1,80 \\
\hline $\mathrm{t}$ & $1 s 2 s 2 p^{2} P_{1 / 2}-1 s^{2} 2 s^{2} S_{1 / 2}$ & 3,9660 & 3,9665 & 3,36 \\
\hline $\mathrm{m}$ & $1 s 2 p^{22} S_{1 / 2}-1 s^{2} 2 p^{2} P_{3 / 2}$ & 3,9629 & 3,9634 & 2,60 \\
\hline $\mathrm{y}$ & $1 s 2 p^{3} P_{1}-1 s^{2 l} S_{0}$ & 3,9671 & 3,9674 & - \\
\hline$q$ & $1 s 2 s 2 p^{2} P_{3 / 2}-1 s^{2} 2 p^{2} S_{1 / 2}$ & 3,9784 & 3,9787 & 0,98 \\
\hline $\mathrm{k}$ & $1 s 2 p^{22} D_{3 / 2}-1 s^{2} 2 p^{2} P_{1 / 2}$ & 3,9875 & 3,9878 & 16,67 \\
\hline $\mathrm{r}$ & $1 s 2 s 2 p^{2} P_{1 / 2}-1 s^{2} 2 s^{2} S_{1 / 2}$ & 3,9808 & 3,9811 & 2,75 \\
\hline $\mathrm{a}$ & $1 s 2 p^{2}{ }^{2} P_{3 / 2}-1 s^{2} 2 p^{2} P_{3 / 2}$ & 3,9831 & 3,9835 & 3,48 \\
\hline $\mathrm{j}$ & $1 s 2 p^{22} D_{5 / 2}-1 s^{2} 2 p^{2} P_{3 / 2}$ & 3,9917 & 3,9923 & 22,93 \\
\hline $\mathrm{Z}$ & $1 s 2 s p^{3} S_{1}-1 s^{21} S_{0}$ & 3,9916 & 3,9919 & - \\
\hline
\end{tabular}

Table 2

Calculated (this paper) wavelengths and satellite intensity factors $\left(\lambda\right.$ in $\AA ; F_{2}{ }^{*}$ in $\left.10^{13} \mathrm{~s}^{-1}\right)$ : Sc, V

\begin{tabular}{|c|c|c|c|c|c|}
\hline Line & Array & $\lambda(\mathrm{Sc})$ & $F_{2}{ }^{*}(\mathrm{Sc})$ & $\lambda(\mathrm{V})$ & $F_{2}{ }^{*}(\mathrm{~V})$ \\
\hline $\mathrm{w}$ & $1 s 2 p^{1} P_{1}-1 s^{21} S_{0}$ & 2,8699 & - & 2,3790 & - \\
$\mathrm{X}$ & $1 s 2 p^{3} P_{2}-1 s^{21} S_{0}$ & 2,8807 & - & 2,3869 & - \\
$\mathrm{s}$ & $1 s 2 s 2 p^{2} P_{3 / 2}-1 s^{2} 2 s^{2} S_{l / 2}$ & 2,8818 & 2,47 & 2,3880 & 2,57 \\
$\mathrm{t}$ & $1 s 2 s 2 p^{2} P_{I / 2}-1 s^{2} 2 s^{2} S_{1 / 2}$ & 2,8829 & 6,78 & 2,3889 & 8,98 \\
$\mathrm{~m}$ & $1 s 2 p^{22} S_{1 / 2}-1 s^{2} 2 p^{2} P_{3 / 2}$ & 2,8813 & 3,57 & 2,3879 & 4,17 \\
$\mathrm{y}$ & $1 s 2 p^{3} P_{1}-1 s^{2 I} S_{0}$ & 2,8846 & - & 2,3910 & - \\
$\mathrm{q}$ & $1 s 2 s 2 p^{2} P_{3 / 2}-1 s^{2} 2 p^{2} S_{l / 2}$ & 2,8903 & 0,48 & 2,3943 & 0,21 \\
$\mathrm{k}$ & $1 s 2 p^{2} D_{3 / 2}-1 s^{2} 2 p^{2} P_{1 / 2}$ & 2,8953 & 25,90 & 2,3979 & 30,82 \\
$\mathrm{r}$ & $1 s 2 s 2 p^{2} P_{1 / 2}-1 s^{2} 2 s^{2} S_{1 / 2}$ & 2,8928 & 3,93 & 2,3971 & 4,89 \\
$\mathrm{a}$ & $1 s 2 p^{22} P_{3 / 2}-1 s^{2} 2 p^{2} P_{3 / 2}$ & 2,8931 & 6,48 & 2,3965 & 8,78 \\
$\mathrm{j}$ & $1 s 2 p^{2} D_{5 / 2}-1 s^{2} 2 p^{2} P_{3 / 2}$ & 2,8991 & 35,54 & 2,4015 & 43,30 \\
$\mathrm{Z}$ & $1 s 2 s p^{3} S_{I}-1 s^{21} S_{0}$ & 2,9005 & - & 2,4031 & - \\
\hline
\end{tabular}

In table 1 we present the calculated wavelengths and satellite intensity factors ( 1 in $\AA ; F_{2}{ }^{*}$ in $10^{13} \mathrm{~s}^{-1}$ ) for the multicharged ion of Ar. The corresponding data have been received on the basis of calculations within the multi-configuration intermediate-coupling scheme with a statistical Thomas-Fermi potential (ref. [2]) and our scheme. A detailed comparison with experiment [2] shows that our data are a little in more good agreement with experimental data than data [2]. In table 2 we present the calculated in this paper wavelengths and satellite intensity factors ( 1 in $\mathrm{E} ; F_{2}{ }^{*}$ in $\left.10^{13} \mathrm{~s}^{-1}\right)$ for the multicharged ion of Sc and V. Numerical evaluation for the most prominent satellite line $\mathrm{j}$ (see table 1) shows that $\varepsilon_{q} / \varepsilon_{w} \sim z^{n}$, where $\mathrm{n}=7,08$ (n is very weakly $\mathrm{T}_{\mathrm{e}}$ dependent between 1000 and $2000 \mathrm{eV}$ ). The evaluated value of the electron temperature is $\sim 1570 \mathrm{eV}$, which is very good agreed with experimental values [2].

So, the carried out calculation of the wave- 
lengths and atomic characteristics of satellite spectrum of the He-like ions from $\mathrm{Ar}^{16+}$ to $\mathrm{Mn}^{23}$ and evaluation of the TFR plasma parameters (electron temperature) shows that theoretical spectroscopy scheme, based on the using new QED method of calculating the multicharged ions spectroscopic characteristics, can be widely used for sensing and diagnostics the tokamak plasma parameters.

\section{References}

1. Rosmej F.B., Hoffman D.H., Geissel M. et al, Advanced X-ray diagnostics based on an observation of high-energy Rydberg transitions from autoionizing levels in dense laser-produced plasmas// Phys. Rev.A. - 2001-Vol.63. P.063409-063418.

2. TFR group, Cornille M., Dubau J., Loulergue M. Chare-dependent wavelengths shifts and line intensities in the dielectronic satellite spectrum of helium-like ions// Phys.rev.A. — 1985. Vol.32,N5. - P.3000-3010.

3. Aglitsky E.V., Safronova U.I. Spectroscopy of autoionization states of atomic systems. Moscow: Nauka, 1985.

4. Chenais-Popovics C., Rancu O., Renaudin P., Gauthier J.C. X-ray Spectroscopy of LaserProduced Hot Dense Plasmas// Phys.Scripta. 1996. - Vol.65,N1. - 163-168.

5. Seely J.F., Ekberg J.O. Brown C.M. et al, Laser Produced Spectra and QED Effects for Fe-, $\mathrm{Co}-, \mathrm{Cu}-$, Zn-like ions of $\mathrm{Au}, \mathrm{Pb}, \mathrm{Bi}, \mathrm{Th}$, and U// Phys.Rev.Lett. - 1996. - Vol.57,N23. - P.2924-2926.

6. Mohr P.J. Quantum Electrodynamics Calculations in few-Electron Systems// Phys.Scripta. — 1993. Vol.46,N1. - P.44-52.

7. Blundell S.A. Ab initio Calculations of QED Effects in Li-like, Na-like and Cu-like Ions// Phys.Scripta. - 1993. - Vol.46,N1. - P.144-150.

8. Ivanova E.P., Ivanov L.N. Modern Trends in Spectroscopy of Multicharged Ions// Physics Rep. — 1991. - Vol.166,N6. - P.315-390.
9. Ivanov L.N., Ivanova E.P., Knight L. Energy Approach to consistent QED theory for calculation of electron-collision strengths//Phys.Rev.A. 1993. - Vol.48,N6. - P.4365-4374

10. Glushkov A.Deuterium lines spectra analysis in Tokamak// Proc. $24^{\text {th }}$ Europ. Conf. on Thermonucl. Fusion and Plasma Physics (Garching, Germany). - 1996.

11. Glushkov A.V., Ivanova E.P. Theoretical Study of Multicharged Ions Spectra of $\mathrm{Na}, \mathrm{Ne}$ Isoelectronic Sequence// J.Quant.Spectr. Rad.Transfer. - 1986. - Vol.36, N2. - P.127-145.

12. Glushkov A.V. Negative Ions of Inert Gases// JETP Lett. - 1992. - Vol.55, N2- C.95-98.

13. Glushkov A.V., Ivanov L.N. Radiation Decay of Atomic States: atomic residue and gauge noninvariant contributions// Phys. Lett.A. - 1992. Vol.170,N1. - P.33-37.

14. Glushkov A.V., Ambrosov S.V., Svinarenko A.A. etal, QED calculation of the super heavy elements ions: energy levels and hyperfine structure for different nuclear models// Nucl. Phys.A. - 2004. - Vol. 734. - P.E21-24.

15. Glushkov A.V.,Malinovskaya S.V., Svinarenko A.A., Chernyakova Yu.G., QED Calculation of Electron Satellites Spectra in Intense Laser Field in Multicharged Ion//Int.J.Quant.Chem. — 2004. Vol.99,N5. - P.673-678.

16. Glushkov A.V., Khetselius O.Yu., Vitavetskaya L.A. Quantum mechanical calculation of the hadronic atoms and superheavy ions: shifts and widths, hfs for different nuclear models//Proc. of the International conference "Nuclei at the Limits" (Argonne National Laboratory, USA). 2004.

17. Chernyakova Yu.G., Prepelitsa G.P., Shumlyansky I.I. Satellite structure of the emission lines of the $\mathrm{Cu}$ plasma in a low inductive vacuum spark// Photoelectronics. - 2002. — Vol.11. P.59-61.

18. Chernyakova Yu.G., Relativistic perturbation theory calculation of the satellite structure of the 23 Ne-like lines// Uzhgorod Univ. Sci. Herald. Ser. Phys. — Math. — 2001. — Vol.10. — P.331-335 